\title{
Experimental Investigations of Mechanical Properties of Sisal Fiber / Cashew nut shell dust Strengthened Hybrid Epoxy Composites
}

\author{
R. Ramamoorthi, R. Soundararajan and R. Jeyakumar
}

Department of Mechanical Engineering, Sri Krishna College of Engineering and Technology, Coimbatore - 641008, Tamil Nadu, India; ramamoorthi@skcet.ac.in, soundararajan@skcet.ac.in, jeyakumar@skcet.ac.in

\begin{abstract}
Objective: To identify a natural fiber and secondary filler and manufacture the hybrid natural fiber composite. To investigated the mechanical characteristics of the manufactured composite laminate. Methodology: The natural fibers and secondary fillers are reinforced into matrix and compression molding machine is used for manufacturing the composite. Finding: It is identified that the mechanical characteristics of the composite laminates are enhanced by the incorporation of natural fillers. The outcome of experimental measurements revealed that $6 \mathrm{wt} \%$ cashew nut shell dust filler reinforced composite laminates exhibited the highest improvement in the measured mechanical properties as compared to the other combinations. Applications: The attained mechanical properties are compared with other unfilled composite laminate manufactured under same process steps. The eco-friendly composite acquired can be utilized in the zone of plastics in the perception of viable growth.
\end{abstract}

Keywords: Cashew Nut Shell Dust Filler, Epoxy, Hybrid Composite, Natural Fiber, Polymer Composite

\section{Introduction}

Composite materials are progressively utilized as a substitute for much conventional material. Due to the rapid development of technologies in industries, observing the progress of inventive material designs for replacement is imperious. Consequently, Polymer composites are recognized as an eminent substitute material because of its low weight and higher strength, with economically feasible aspects. Currently, growing technological field has been paved a way to the utilization of eco-friendly resources, particularly the plant origin keeping the ecological concerns and renewability aspects. Currently, natural-fiber composites have expanded attention towing to their ecofriendly properties.

Lots of effort has been taken by researcher on these natural-fibers. Subsequently natural fibers are inexpen- sive, plenty, renewable, lighter in weight, little density, extraordinary toughness, and bio-degradable. So by using these fibers the composite produced is cost effective and seamless exploitation of waste products.

In compared life cycle environmental, concert of natural-fiber composites with glass fiber reinforced composites and establish that natural-fiber composites are naturally superior in the specific applications which they have studied considered ${ }^{1}$. In have converted the bagasse into a thermo formable material. The dimensional steadiness and mechanical performance of the composites prepared from esterifies fibers were reported in this work ${ }^{2}$. In developed coir composite and mechanical properties were evaluated. Scanning electron micrographs obtained from fracture surfaces were used for a qualitative evaluation of the interfacial properties of coir /epoxy and compared with glass fibers ${ }^{3}$. Similarly various researchers

*Author for correspondence 
identified, manufactured and evaluated the mechanical properties and proved that the they has been enhanced appreciably ${ }^{4-8}$.

The process of mingling particulate reinforcements to construct hybrid natural-fiber composites is prevalent as it permits the enhancements of mechanical characteristics of the resultant composite. Fabricated coir-fiber strengthened polyester composites with calcium carbonate as additional reinforcement and examined the mechanical features. They detailed that the incorporation of 2 percentage of calcium carbonate improved the mechanical properties in coir-polyester composites ${ }^{9}$. In made the of fly ash infused glass fiber armored composites by changing the filler content and explored the mechanical characteristics of the composites. They have described that the incorporation of fillers amplified the mechanical properties of composites $^{10}$.

It is understood from the above literatures, in this new era, the prominence has been given to develop the composite materials from agricultural based renewable resources which are available locally.

The objective of this current research work is to develop the sisal fiber reinforced hybrid epoxy composites along with the different weight proportions (viz. $2 \%, 4 \%, 6 \%$ and $8 \%$ ) of cashew nut shell dust as secondary filler and to investigate the effect of the weight percentage of CNSD on the mechanical properties of the composites.

\section{Materials and Experimental Procedures}

\subsection{Materials}

\subsubsection{Reinforcement Preparation}

The raw sisal fibers were cleaned and treated with five percentage $\mathrm{NaOH}$ for $1 \mathrm{~h}$ and washed in diluted acid followed by distilled water to remove wax, lignin, oils and other fiber constituents that may reduce grip among the matrix/ fibers thereby constituting a weak boundary layer the non-reacted alkali. Then the fibers were withered in an air-oven at $70^{\circ} \mathrm{C}$ for 3 hours. This treated sisal fiber is used as primary reinforcement.

The dried cashew nut shells were crushed to obtain the CNSD fillers. The fillers were dried in sunlight for 48 hours and then further dried in an oven for an hour at $70^{\circ} \mathrm{C}$ to obtain completely dry fillers ${ }^{11}$. This CNSD were used as secondary reinforcements.

\subsection{Matrix Materials}

Epoxies have found a special place in the family comprising thermo set engineering polymers because of their excellent mechanical properties with chemical and corrosion resistance. Moulded or cast epoxies have excellent dimensional stability and low shrinkage. Hence, these are used as dies for stamping metal sheets and as models for production articles. Another attribute, which has placed epoxies above others, is the easy process ability with the addition of a curing agent and with or without application of heat ${ }^{12}$. Due to these several advantages the medium viscosity epoxy resins 'LY 556' and hardener 'HY 951' is used in this study.

\subsection{Fabrication of Composite Laminate}

Epoxy resin LY556 grade was warmed to reduce the viscosity in order to facilitate superior wetting of the particles. For composite preparation a definite quantity of cashew nut shell dust is agitated in preheated epoxy resin by mechanical stirrer to endorse even fusion of particles. To reduce the risks of voids, further the fillers dispersed resin is retained in vacuum for $30 \mathrm{~min}$. After the bubbles were confined, balanced quantity of hardener HY951 was dispensed and mixed by manual stirring for 5-10 minutes. Through the fabrication of composite laminate, the interior faces of the mold plates were sprayed with a thinly coat of releasing agent for easy removal of the composite laminate.

Hand lay-up technique was adopted to fill the prepared mould cavity with an appropriate amount of modified matrix resin and sisal fiber, starting and finishing with coats of resin. Fiber movement should be lessened to get noble quality laminates. Therefore at the time of curing, a compressive pressure of 1500 Psi was applied on the mould and the specimens were cured for 24hours and laminates were also post cured at $70^{\circ} \mathrm{C}$ for $2 \mathrm{hrs}$ after removing from the mould. Table 1 shows the details of weight proportions of various elements. Figure 1 shows the sisal fiber, CNSD used for composite fabrication and sample manufactured laminate. 


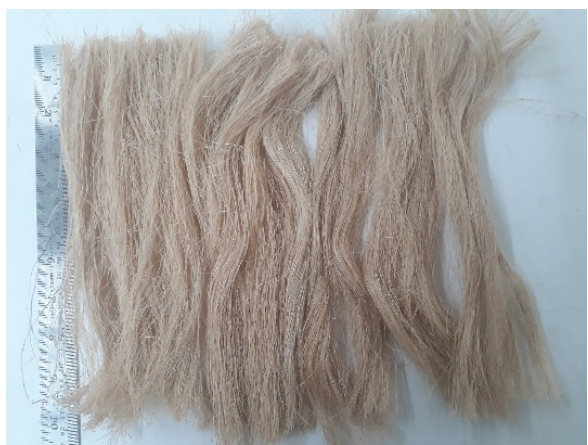

A

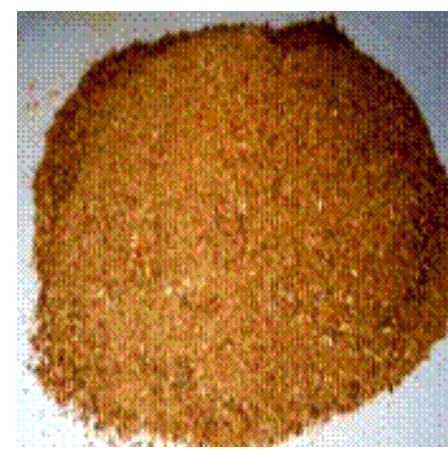

B

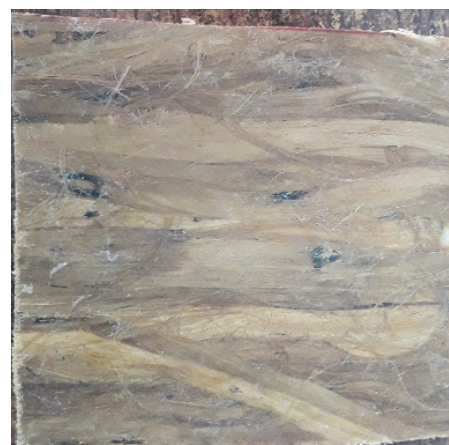

C

Figure 17. A) Sisal Fiber, B) CNSD Filler, and C) Manufactured laminate.

Table 1. Weight proportions of elements of composites

\begin{tabular}{|c|c|c|c|}
\hline \multirow{2}{*}{ Designation } & \multicolumn{3}{|c|}{ Weight proportion (\%) } \\
\cline { 2 - 4 } & Matrix & Fiber & Filler \\
\hline A & 70 & 30 & 0 \\
\hline B & 70 & 28 & 2 \\
\hline C & 70 & 26 & 4 \\
\hline D & 70 & 24 & 6 \\
\hline E & 70 & 22 & 8 \\
\hline
\end{tabular}

\subsection{Characterization}

The samples are cut from the resultant composite laminates and the tensile strength, impact strength, flexural strength tests are performed as per the ASTM standards.

\subsubsection{Tensile Strength}

Ultimate tensile strength (UTS) is the maximum stress that a material can withstand while being stretched or pulled before necking, which is when the specimen's cross-section starts to significantly contract. Tensile strength was tested by a Kalpak universal testing machine according to the procedure described in standard ASTM D3039-76 with a cross-head speed of $2 \mathrm{~mm} / \mathrm{min}$. The samples were cut from composite sheets having dimensions $250 \mathrm{~mm} \times 25 \mathrm{~mm} \times 3 \mathrm{~mm}$.

\subsubsection{Impact Strength}

Impact properties of the composite material are directly related to its overall toughness. The Izod impact test is carried out using a pendulum impact system, according to ASTM D256.The composite samples were tested unnotched. The test specimen was supported as a vertical cantilever beam and broken by a single swing of a pendu- lum. The impact energy is calculated based on the height to which the striker would have risen, if no test specimen was in place, and this is compared to the height to which the striker actually rises, the sample having the dimensions of $66 \mathrm{~mm} \times 13 \mathrm{~mm} \times 3 \mathrm{~mm}$.

\subsubsection{Flexural Strength}

Flexural strength is the maximum stress developed when the bar-shaped composite test specimen acting as a simple beam, is subjected to a bending force perpendicular to the bar. The flexural strength represents the highest stressbearing capacity of the material at its moment of rupture. Flexural tests under three-point bend configuration were performed according to the ASTM D790, on a universal testing machine to evaluate flexural modulus and strength of each of the laminates. The span to depth ratio was maintained at 16:1. The maximum stress at failure on the tension side of a flexural specimen was considered as the flexural strength of the material. The samples have the dimensions $126 \mathrm{~mm} \times 13 \mathrm{~mm} \times 3 \mathrm{~mm}$.

The Figure 2 shows the instruments used for measuring the above properties.

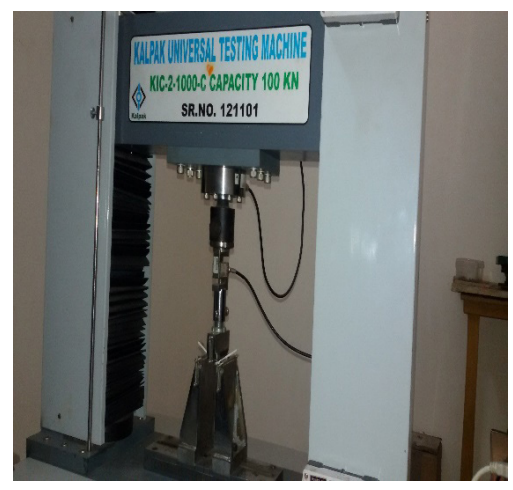

A 


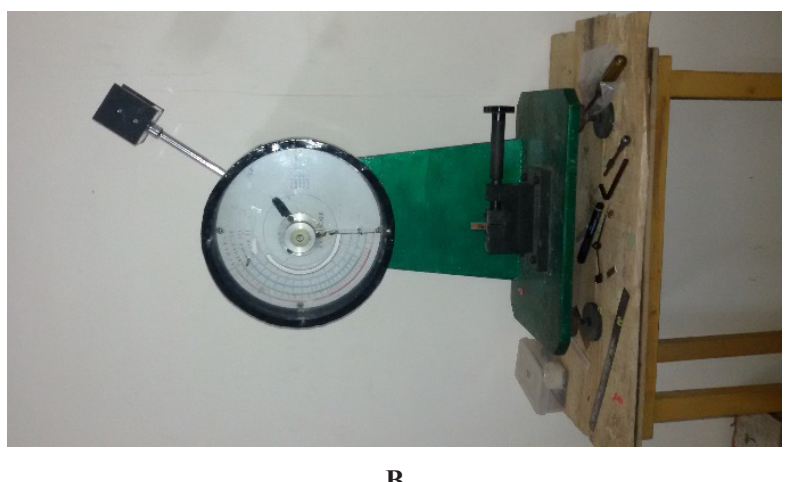

Figure 2. A. Universal Testing Machine, and B. Impact Testing Machine.

\section{Results and Discussion}

The data relates to mechanical properties of the composite laminate are presented and discussed in the following sections.

\subsection{Tensile Strength}

The effects of CNSD loading on the tensile strength of EP/ Coir/CNSD hybrid composites are presented in Figure 3.

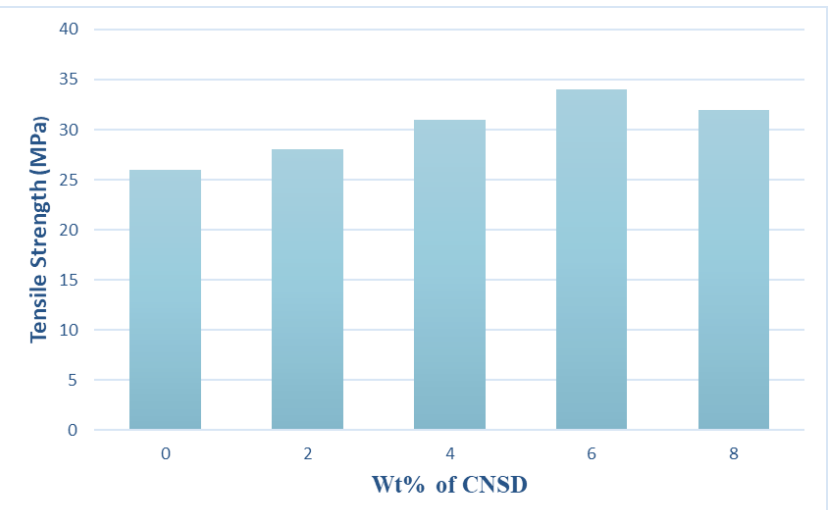

Figure 3. CNSD Wt\% vs tensile strength.

From Figure 3, it is established that the rise in wt \% of CNSD in epoxy resin leads to gradual escalation in the tensile strength. This is because of the mutual action of CNSD and sisal fiber to the epoxy resin, which finally increases the load withstanding capability of the resultant composite. It is observed that the maximum tensile strength is obtained at $6 \mathrm{wt} \%$ addition of CNSD which is $31 \%$ higher than the tensile strength of unfilled epoxy/ sisal fiber composite. But further addition of CNSD i.e. $8 \mathrm{wt} \%$ addition the improvement in tensile strength is only $23 \%$. So there is no significant improvement in tensile strength, since more addition of filler may result in poor wetted fiber which in turn inexpert the stress transfer surfaces and finally this leads to saturation of tensile strength. Therefore $6 \mathrm{wt} \% \mathrm{CNSD}$ addition is considered as an optimum level of filler loading.

\subsection{Impact Strength}

The Figure 4 displays the impact strength with respect to the $\mathrm{wt} \%$ of the composite.

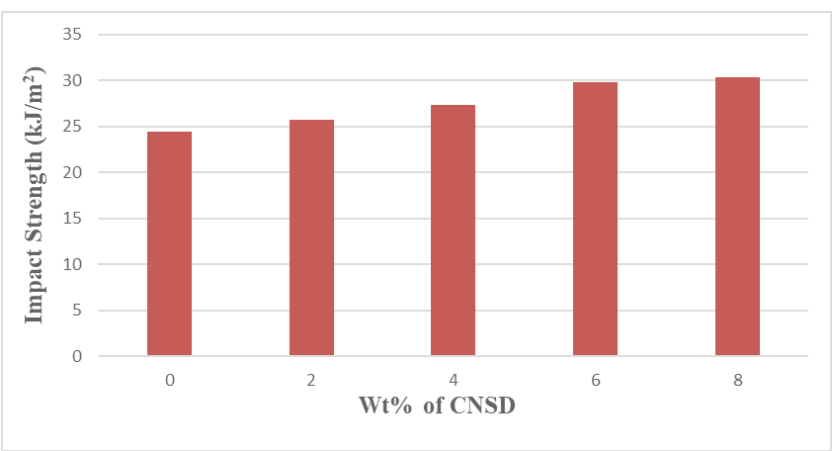

Figure 4. CNSD wt\% vs impact strength.

It is understood from Figure 3 that the increase in wt $\%$, leads to escalation in impact strength since the filler material is capable of taking extra energy and avert the crack proliferation. The enrichment of the impact strength might be owing to softening effect presented by natural fillers. The improvement in impact strength at $8 \mathrm{wt} \%$ as compared with unfilled composite laminate is $24.6 \%$. But the trend shows after $6 \mathrm{wt} \%$ addition of CNSD, the enhancement in the impact strength not more. This may due to improper wetting of fibers and fillers.

\subsection{Flexural Strength}

The Figure 5 shows the effect of CNSD filler wt $\%$ on the flexural strength of the composite laminates. It is detected that the flexural strength is improved by increasing the weight proportion of the CNSD filler weight proportion. At $4 \mathrm{wt} \%, 6 \mathrm{wt} \%$ and $8 \mathrm{wt} \%$ additions of CNSD filler the improvement in the flexural strength are $17.2 \%$ , $37.2 \%$ and $38 \%$ as compared with the unfilled composite laminate, it is understood from the above values the improvement percentage of the flexural strength is alleviates after $6 \mathrm{wt} \%$ addition of CNSD. This also may be due to weak interfacial bonding between matrix and fiber/filler. 


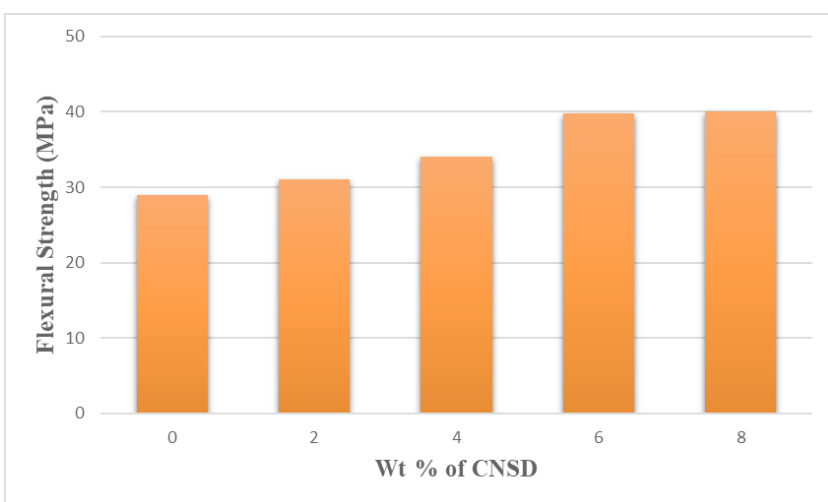

Figure 5. CNSD wt\% vs flexural strength.

\subsection{SEM Micrograph Studies}

The Figure $6 \mathrm{~A}, 6 \mathrm{~B}$ and $6 \mathrm{C}$ shows the SEM micrograph of fractured surface of sisal fiber reinforced unfilled, $6 \mathrm{wt} \%$ filled and 8wt\% epoxy composites.

It is observed from Figure 6A, that more amount of fiber pull out in several directions from the matrix without adherent resin. This designates deprived bond between the fiber and matrix. Figure $6 \mathrm{~B}$ indicates that the robust adhesion among the fiber and matrix system, which diminishes the individual fiber pullout along the presence of cracks at the broken surface. So this results in improvement of strength properties of the composites. The Figure 6C shows pull out of certain fibers along with the existence of cracks at the broken surface, it also shows some of the agglomerations which may cause improper curing of matrix those results in reduction of the mechanical properties. Even though this illustrates appreciable degree of adhesion between the fiber and matrix as compared with unfilled sisal epoxy composite.

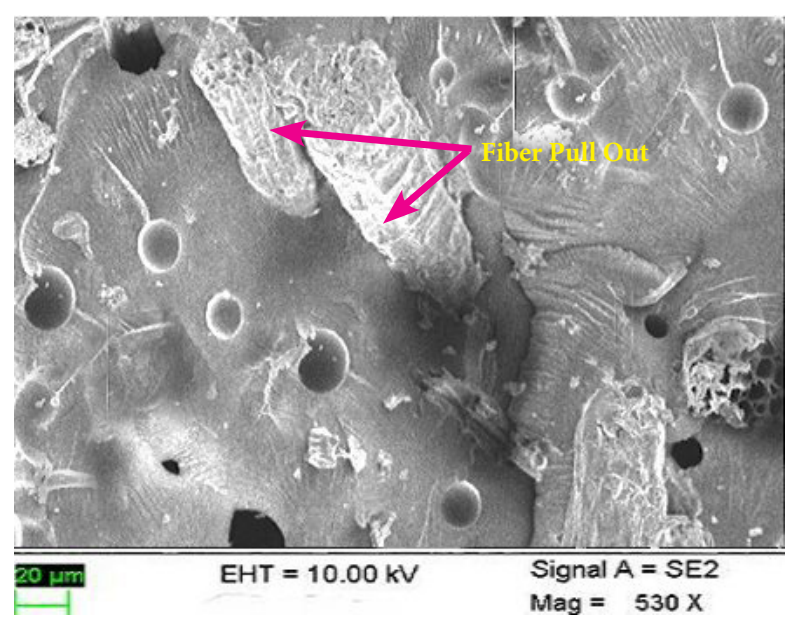

A

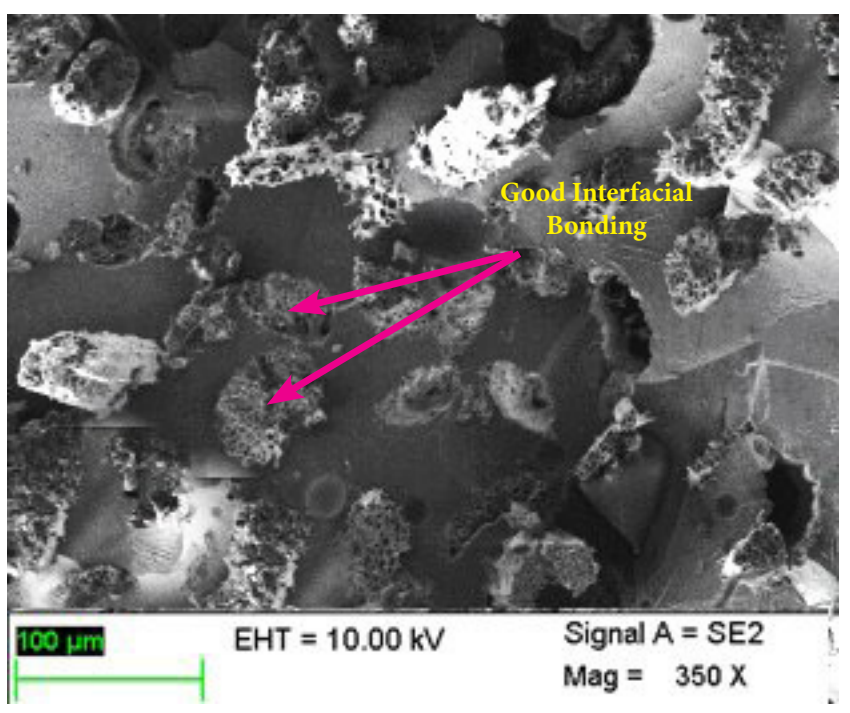

B

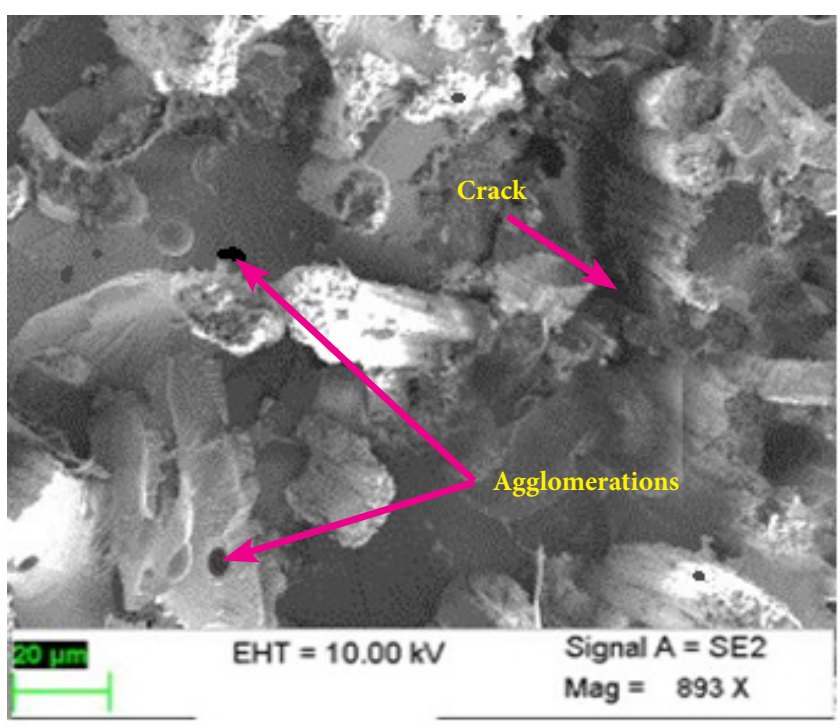

C

Figure 6. SEM micrograph of EP/sisal composite with A. 0wt \%; B. 6 wt \% and C. 8 wt \% CNSD fillers.

\section{Conclusion}

The effects of the incorporation of different weight proportions of Cashew Nut Shell Dust (CNSD) fillers on the mechanical behaviours of sisal fiber reinforced sisal fiber (Epoxy/Sisal) composites were investigated. The investigations revealed that noticeable improvement in the measured properties with the addition of CNSD fillers. Especially addition $6 \mathrm{wt} \%$ fillers results best improvement in the mechanical properties but after that the improvement in the properties are saturated. These results were 
clearly confirmed by morphological analysis, in which it was observed that the fibers present a good interaction by the epoxy due to the addition of CNSD fillers. On the basis of these results, it is possible to correlate a good fiber-matrix adhesion at the interface with an improvement of the composite properties.

\section{References}

1. Joshi SV, Drzal LT, Mohanty AK, Arora S. The mechanical properties of vinyl ester resin matrix composites reinforced with alkali-treated jute fibres, Composites Part A: Applied Science and Manufacturing. 2001; 32(1):119-27. https:// doi.org/10.1016/S1359-835X(00)00101-9.

2. Hassan ML, Rowell RM, FadlNA, YacoubSF, Chrisainsen AW. Thermo plasticization of bagasse. II. Dimensional stability and mechanical properties of esterified bagasse composite, Journal of Applied Polymer Science. 2000; 76(4):575-86. https://doi.org/10.1002/(SICI)1097-4628(20000425) 76:4<575::AID-APP15>3.0.CO;2-9.

3. Harish S, Peter MichaelD, Bensely A, Mohan LalD, Rajadurai A. Mechanical property evaluation of natural fiber coir composite, Materials Characterization. 2008; 60(1):44-49. https://doi.org/10.1016/j.matchar.2008.07.001.

4. Hu R, Lim JK. Fabrication and mechanical properties of completely biodegradable hemp fiber reinforced polylactic acid composites, Journal of Composite Materials. 2007; 41(13):1655-69. https://doi.org/10.1177/ 0021998306069878.

5. Ashori A, Nourbakhsh A. Wood plastic composites from agro-waste materials: Analysis of mechanical properties, Bioresource Technology. 2010; 101(7):2525-28. https://doi. org/10.1016/j.biortech.2009.11.040. PMid:20004095.
6. Lee BH, Kim HJ, Yu WR. Fabrication of long and discontinuous natural fiber reinforced polypropylene biocomposites and their mechanical properties, Fibers and Polymers. 2009; 10(1):83-90. https://doi.org/10.1007/s12221-009-0083-z

7. Duigou AL, Deux JM, Davies P, Baley C. PLLA/Flax Mat/ Balsa bio-sandwich manufacture and mechanical properties, Applied Composite Materials. 2011; 18(5):421-38. https://doi.org/10.1007/s10443-010-9173-8.

8. Zaman HU, Beg M. Preparation, structure, and properties of the coir fiber/polypropylene composites, Journal of Composite Materials. 2014; 48(26):3293-301. https://doi. org/10.1177/0021998313508996.

9. Sathiyamurthy S, Thaheer ASA, Jayabal S. Mechanical behaviors of calcium carbonate-impregnated short coir fiber-reinforced polyester composites, Proceedings of the Institution of Mechanical Engineers, Part L: Journal of Materials Design and Applications. 2012; 226(1):52-60.

10. Satheesh Raja R, Manisekar K, Manikandan V. Study on mechanical properties of fly ash impregnated glass fiber reinforced polymer composites using mixture design analysis, Materials and Design. 2014; 55:499-508. https://doi. org/10.1016/j.matdes.2013.10.026.

11. Sathishkumar T, Navaneethakrishnan P, Shankar S, Rajasekar R, Rajini N. Characterization of natural fiber and composites - A review, Journal of Reinforced Plastics and Composites. 2013; 32(19):1457-76. https://doi.org/ $10.1177 / 0731684413495322$.

12. Ramamoorthi R, Sampath PS. Experimental investigations of influence of halloysite naotube on mechanical and chemical resistance properties of glass fiber reinforced epoxy nano composite, Journal of Scientific and Industrial Research. 2015; 74:685-89. 